\title{
Retinal Vasculitis Secondary to Durvalumab
}

\author{
Antonio R. Andrade ${ }^{a}$ Aina Moll-Udina ${ }^{b} \quad$ Ruth Martin $^{a} \quad$ Esther Cilveti $^{\mathrm{a}}$ \\ Olaia Subirà ${ }^{a} \quad$ Laura Disfetano $^{a}$ Jose García-Arumía \\ aphthalmology Department, Vall d'Hebron, Facultat de Medicina, Universitat Autònoma \\ de Barcelona, Barcelona, Spain; ${ }^{b}$ Ophthalmology Department, Hospital Clínic de \\ Barcelona, Instituto Clínic de Oftalmología, Barcelona, Spain
}

\section{Keywords}

Vasculitis · Retina $\cdot$ Checkpoint inhibitors · Cancer therapy $\cdot$ Durvalumab

\begin{abstract}
Ocular manifestations are very rarely reported as side effects to checkpoint inhibitors. We present a case of a 64-year-old Caucasian man in treatment with durvalumab for non-small-cell lung carcinoma who presented a retinal vasculitis with macular edema. After three boluses of methylprednisolone, the retinal vasculitis resolved and macular edema improved during follow-up. There was no need for durvalumab to be withdrawn.

(C) 2020 The Author(s) Published by S. Karger AG, Basel
\end{abstract}

\section{Introduction}

In recent years, checkpoint monoclonal antibodies have occupied a very significant role in the immune-mediated antitumor response, serving as a complement to traditional approaches to cancer. Tumor cells can mislead the immune system to downregulate its responses. Immune checkpoint drugs intervene in the immunological synapse, leading to a higher activation of effector T cells [1].

Durvalumab is one of many monoclonal antibodies approved for the treatment of urothelial tumors and is currently under investigation for the treatment of other malignancies [2]. It is often used off-label to treat squamous carcinoma, small-cell lung cancer, and non-small-cell 
lung carcinoma. As a programmed death-ligand 1 (PD-L1) inhibitor, durvalumab works blocking the interaction between programmed cell death protein (PD-1), present on T cells, and PDL1, present on tumor cells, resulting in a higher activity of the immune system [3].

The enhancement of the immune response comes with high risk for immune-related adverse effects (irAEs) [2, 3]. Nevertheless, ocular side effects are seldom described in literature [3].

\section{Case Presentation}

A 64-year-old Caucasian man presented with sudden vision loss from his left eye. He suffered from non-small-cell lung carcinoma and had been in treatment with durvalumab 1,125 mg every 3 weeks for the past 20 months. The patient had no signs of other systemic conditions and his arterial blood pressure was normal. Serologies for herpes viruses, human immunodeficiency virus, and T. pallidum were negative. He had no previous history of ophthalmic pathology. His best-corrected visual acuity (BCVA) was 20/20 in his right eye and counting fingers in his left eye. There were no pathological findings in the anterior segment examination. The fundoscopy showed papillitis, dot and blot hemorrhages, intraretinal hemorrhages, severe cystoid macular edema, and mild white sheathing in the macular vascular branches (Fig. 1). Posterior optical coherence tomography (Swept Source OCT, Triton ${ }^{\mathrm{TM}}$, TOPCON, Japan) confirmed the cystoid macular edema associated with hyperreflective material that might be fibrin, secondary to the severe retinal inflammation, as well as vitreous hyperreflective foci. Ultra-wide-field fundus fluorescein angiography (Optos ${ }^{\circledR}$, Optomap ${ }^{\circledR}$, UK) revealed tertiary branch phlebitis and vascular leakage (Fig. 2). The patient was admitted and started on methylprednisolone bolus $500 \mathrm{mg} /$ day for 3 days, followed by methylprednisolone $1 \mathrm{mg} /$ $\mathrm{kg} /$ day for 1 week, and then tapered oral prednisone, starting from $30 \mathrm{mg} /$ day, over 3 weeks. During his admission, the patient was seen daily. In as little as $24 \mathrm{~h}$ after being admitted, the patient referred an ongoing improvement of his visual symptoms, is BCVA was 20/50 by the time the treatment ended, and eventually evolved to 20/25 after 2 months follow-up. During this time, the posterior optical coherence tomography (Swept Source OCT, Triton ${ }^{\mathrm{TM}}$, TOPCON, Japan) registered a gradual reduction of the macular edema (Fig. 3) and the ultra-wide-field fundus fluorescein angiography $\left(\right.$ Optos $^{\circledR}$, Optomap $\left.^{\circledR}, \mathrm{UK}\right)$ a resolution of the ocular vasculitis.

After a 1-year follow-up, the patient showed a complete resolution of this condition, showed no signs of vasculitis or other ocular findings, had no need for rescue treatment, and is currently still on durvalumab without other side effects being reported.

\section{Discussion}

irAEs are commonly reported among patients treated with checkpoint inhibitor drugs. The most frequent irAEs are skin rash and diarrhea [3], although this autoimmune-like reactions can occur throughout the body and produce a vast multitude of findings. Ophthalmologic adverse effects are reported to occur in approximately $1 \%$ of the patients, are less frequent in PD-L1 inhibitor drugs, when compared to other checkpoint inhibitors [3], have a time to onset that ranges from weeks to years after starting therapy, and do not appear to be dose related $[2,3]$. The most frequently reported ocular findings are dry eye and uveitis $[3,4]$. 
Durvalumab has been related with keratitis and uveitis [3] but, despite that, Fang et al. [4] did not find any ocular manifestations related to durvalumab in the FDA's Adverse Events Reporting System (FAERS).

The immunological "handshake" between PD1/PDL1 has been described in the vasculitis immunological pathway [5], and checkpoint inhibitors have been suggested to trigger this vascular inflammation [6]. Daxini et al. [7] demonstrated a correlation between vasculitis and checkpoint inhibitors like anti-PDL-1.

Vasculitis in association with immunotherapy has been reported in other organs [8, 9]. Aaberg and Aaberg Jr. [10] described a case of posterior uveitis and retinal vasculitis associated with pembrolizumab, another type of checkpoint inhibitor drug, in a patient diagnosed with metastatic uveal melanoma witch was treated with an intraocular dexamethasone implant. Acaba-Berrocal et al. [11] reported a case of a birdshot-like chorioretinopathy in a patient with cutaneous melanoma treated with pembrolizumab, which was reverted recurring to periocular triamcinolone.

Ocular immune-related adverse effects are usually treated with corticosteroids, either topically, intraocularly, or systemically [3]. As the use of checkpoint inhibitors arises worldwide, more and more adverse effects are being reported. Prompt diagnosis and treatment can lead to excellent functional prognosis without having to discontinue this vital therapy, so we recommend a close ophthalmological follow-up to all patients undergoing this kind of treatment. In our case, retinal vasculitis recovered after three methylprednisolone boluses, without being necessary to withdraw durvalumab.

Patients with metastatic neoplasm that present ocular inflammation and vision loss must be referred to a complete ophthalmic examination to rule out paraneoplastic syndromes such as cancer-associated retinopathy (CAR), melanoma-associated retinopathy, or neoplastic exudative polymorphous vitelliform maculopathy. CAR is a paraneoplastic autoimmune retinopathy that consists of an immunologic process that involves retinal antigens being aberrantly recognized as autoantigens, leading to diffuse retinal degeneration [12]. CAR is most frequently associated with small-cell lung carcinoma, the usual presenting symptoms being subacute vision loss and visual field constriction [13]. Signs of retinal vasculitis and vitreous cells have been reported in CAR [14,15], but after an initial inflammatory phase, retinal atrophy, retinal pigmental epithelial mottling, and arteriolar attenuation are frequent findings in these patients. In our case, the patient recovered promptly with no retinal damage nor vascular sequelae.

Although the clinical case could also resemble a mild retinal vein occlusion, the presence of inflammatory cells in the vitreous (Fig. 3), the small number of hemorrhages, and the rapid recovery with systemic corticosteroid therapy made us think of a uveitic etiology. Since infectious diseases were ruled out, the patient had no other clinical findings like oral or genital ulcers, and since it was a unilateral vasculitis with mild vitritis, we presumptively associated the retinal vasculitis with durvalumab.

To our knowledge, this is the first case of vasculitis associated with durvalumab. The patient presented with ocular vasculitis and cystoid macular edema in an acute and sight-threatening way, so, due to this aggressive onset, we decided to treat it with systemic corticosteroids bolus, having had an excellent recovery.

\section{Statement of Ethics}

The patient has consented to the submission and publication of the case report, images included. 


\section{Case Reports in Ophthalmology}

\section{Disclosure Statement}

The authors declare no commercial or proprietary conflicts of interest. The authors alone are responsible for the content and writing of the paper.

\section{Funding Sources}

No funding or grant support was received.

\section{Author Contributions}

Antonio R. Andrade, MD: conception of the paper, design of the paper, data analysis and interpretation, manuscript drafting, and literature search. Aina Moll-Udina, MD: co-writing of the manuscript, design of the paper, literature search, manuscript editing and revision, as well as final approval. Ruth Martin, MD, Esther Cilveti, MD: co-writing of the manuscript, literature search. Olaia Subirà, MD: literature search, manuscript editing and revision. Laura Disfetano MD, Jose García-Arumí, MD, PhD: equal contribution of patient management, data collection. All authors state that they approve the paper. All authors attest that they meet the current ICMJE criteria for authorship.

\section{References}

1 Mellman I, Coukos G, Dranoff G. Cancer immunotherapy comes of age. Nature. 2011 Dec;480(7378):480-9.

2 Marrone KA, Ying W, Naidoo J. Immune-Related Adverse Events From Immune Checkpoint Inhibitors. Clin Pharmacol Ther. 2016 Sep;100(3):242-51.

3 Dalvin LA, Shields CL, Orloff M, Sato T, Shields JA. CHECKPOINT INHIBITOR IMMUNE THERAPY: Systemic Indications and Ophthalmic Side Effects. Retina. 2018 Jun;38(6):1063-78.

4 Fang T, Maberley DA, Etminan M. Ocular adverse events with immune checkpoint inhibitors. J Curr Ophthalmol. 2019 Jun;31(3):319-22.

5 Zhang H, Watanabe R, Berry GJ, Vaglio A, Liao YJ, Warrington KJ, et al. Immunoinhibitory checkpoint deficiency in medium and large vessel vasculitis. Proc Natl Acad Sci U S A. 2017 Feb 7;114(6):E970-9.

6 Watanabe R, Zhang H, Berry G, Goronzy JJ, Weyand CM. Immune checkpoint dysfunction in large and medium vessel vasculitis. Am J Physiol Heart Circ Physiol. 2017 May;312(5):H1052-9.

7 Daxini A, Cronin K, Sreih AG. Vasculitis associated with immune checkpoint inhibitors-a systematic review. Clin Rheumatol. 2018 Sep;37(9):2579-84.

8 Tomelleri A, Campochiaro C, De Luca G, Cavalli G, Dagna L. Anti-PD1 therapy-associated cutaneous leucocytoclastic vasculitis: A case series. Eur J Intern Med. 2018 Nov;57:e11-2.

9 Comont T, Sibaud V, Mourey L, Cougoul P, Beyne-Rauzy O. Immune checkpoint inhibitor-related acral vasculitis. J Immunother Cancer. 2018 Nov 16;6(1):120.

10 Aaberg MT, Aaberg TM Jr. PEMBROLIZUMAB ADMINISTRATION ASSOCIATED WITH POSTERIOR UVEITIS. Retin Cases Brief Rep. 2017;11(4):348-51.

11 Acaba-Berrocal LA, Lucio-Alvarez JA, Mashayekhi A, Ho AC, Dunn JP, Shields CL. Birdshot-like Chorioretinopathy Associated With Pembrolizumab Treatment. JAMA Ophthalmol. 2018 Oct 1;136(10):1205-7.

12 Zeng HY, Liu Q, Peng XY, Cao K, Jin SS, Xu K. Detection of serum anti-retinal antibodies in the Chinese patients with presumed autoimmune retinopathy. Graefes Arch Clin Exp Ophthalmol. 2019 Aug;257(8):1759-64.

13 Chan JW. Paraneoplastic retinopathies and optic neuropathies. Surv Ophthalmol. 2003 Jan-Feb;48(1):12-38

14 Anastasakis A, Dick AD, Damato EM, Spry PG, Majid MA. Cancer-associated retinopathy presenting as retinal vasculitis with a negative ERG suggestive of on-bipolar cell pathway dysfunction. Doc Ophthalmol. 2011 Aug;123(1):59-63.

15 Sawyer RA, Selhorst JB, Zimmerman LE, Hoyt WF. Blindness caused by photoreceptor degeneration as a remote effect of cancer. Am J Ophthalmol. 1976 May;81(5):606-13. 


\section{Case Reports in Ophthalmology}

\begin{tabular}{l|l}
\hline Case Rep Ophthalmol 2020;11:161-166 \\
\hline DOI: 10.1159/000507609 & $\begin{array}{l}\text { C 2020 The Author(s). Published by S. Karger AG, Basel } \\
\text { www.karger.com/cop }\end{array}$ \\
\hline
\end{tabular}

R. Andrade et al.: Retinal Vasculitis Secondary to Durvalumab

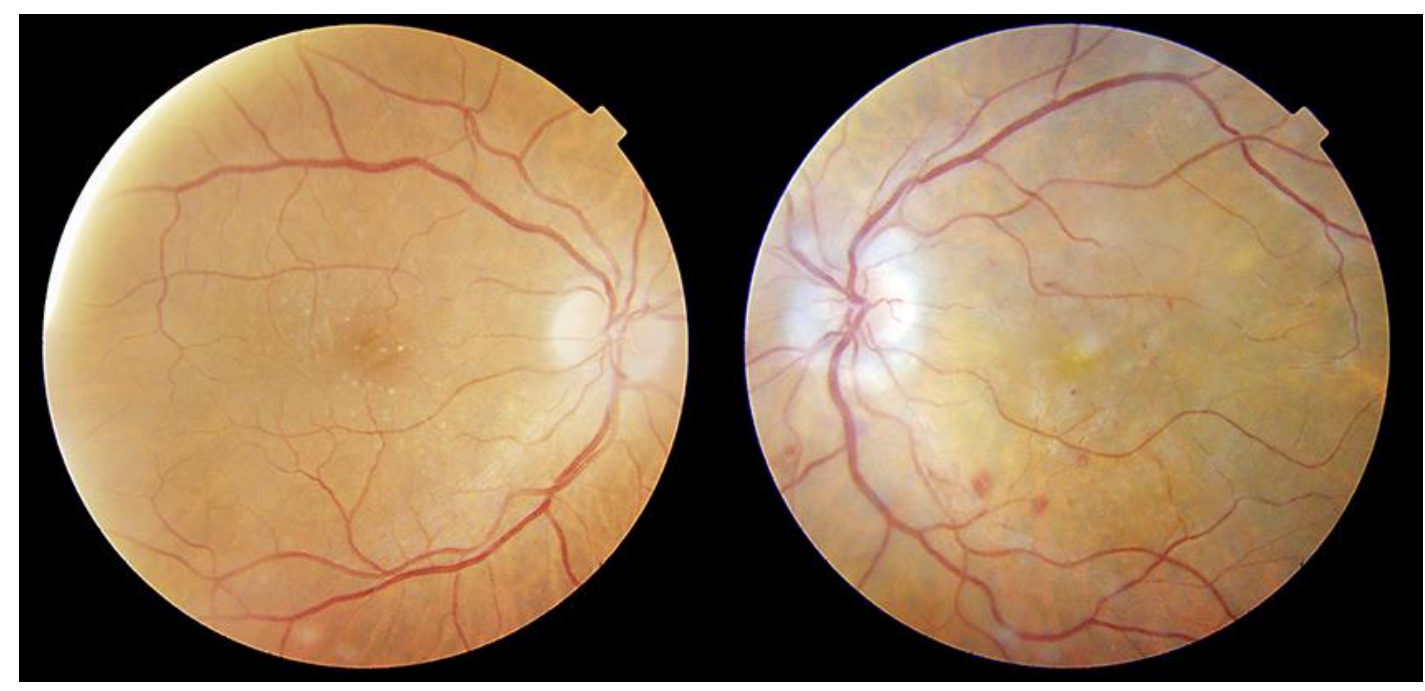

Fig. 1. Color fundoscopy at presentation. Right eye shows macular microdruses. Left eye shows papillitis, hemorrhages, and white sheathing in the macular vascular branches.

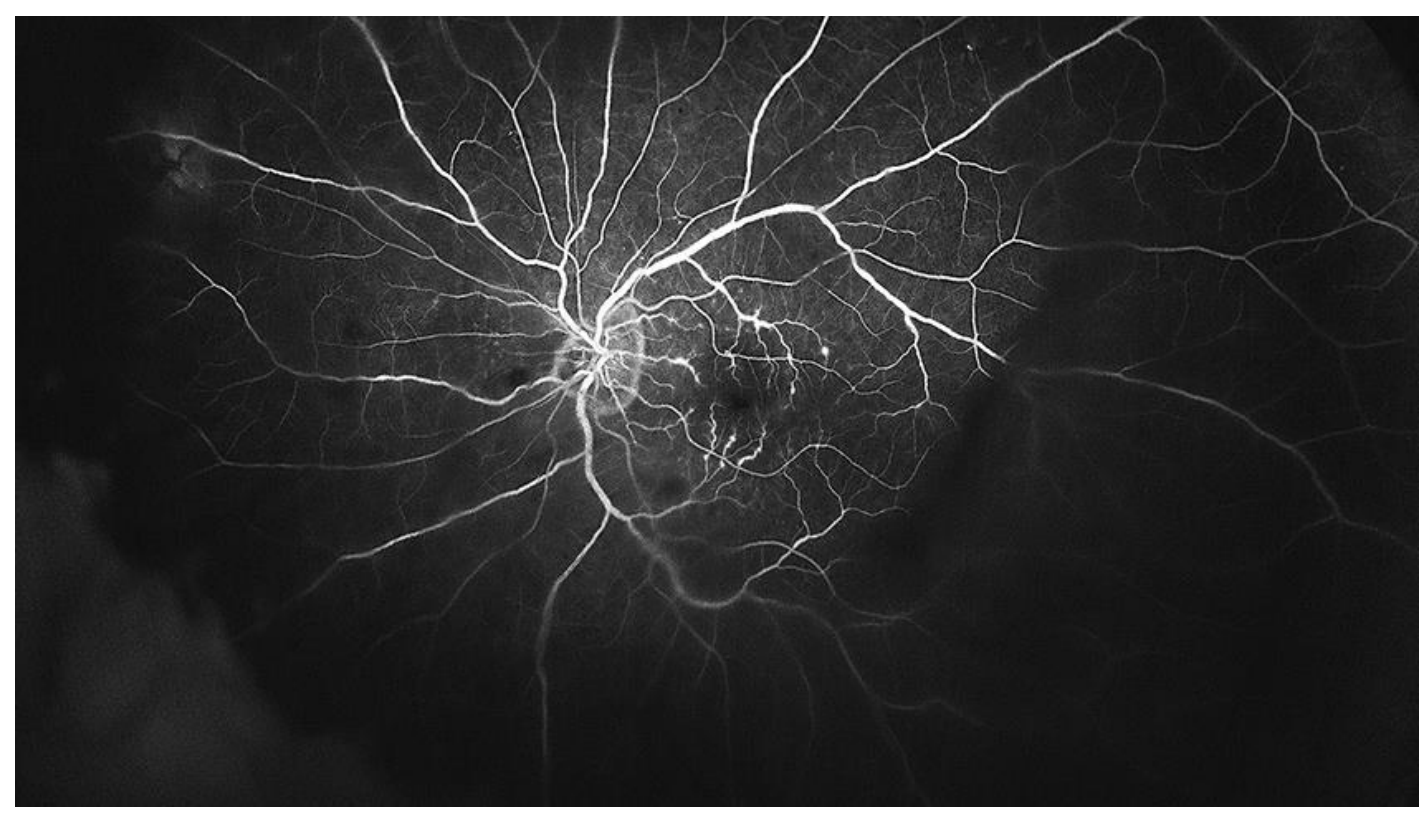

Fig. 2. Ultra-wide-field fundus fluorescein angiography (Optos ${ }^{\circledR}$, Optomap ${ }^{\circledR}$, UK) shows tertiary branch phlebitis and vascular leakage. 


\section{Case Reports in Ophthalmology} www.karger.com/cop

R. Andrade et al.: Retinal Vasculitis Secondary to Durvalumab

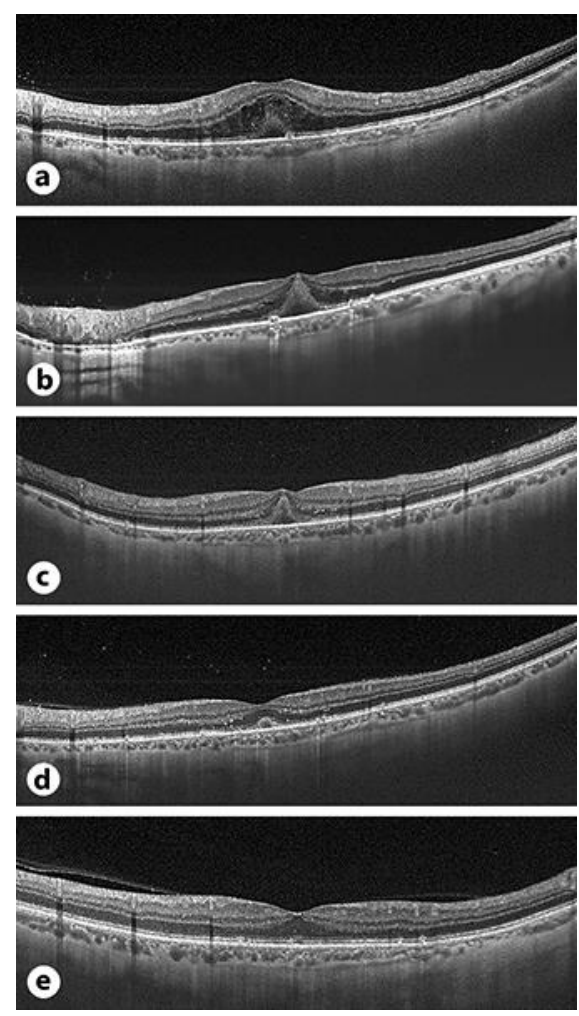

Fig. 3. Optical coherence tomography (Swept Source OCT, Triton ${ }^{\mathrm{TM}}$, TOPCON, Japan) images of the macula (a) at presentation, (b) $24 \mathrm{~h}$ of follow-up, (c) $48 \mathrm{~h}$ of follow-up, (d) 10-day follow-up, and (e) 5-month follow-up. a Cystoid macular edema and subretinal fluid associated with hyperreflective subfoveal material that can be better observed in $\mathbf{b}$ and $\mathbf{c}$ when macular edema is resolving. Vitreous hyperreflective foci are seen in $\mathbf{a}-\mathbf{d}$. 